\title{
The Implementation Model of Poor Farmers Community Empowerment Case Study: Commodity Development at District Strategic Areas In Bone, Indonesia
}

\author{
Anwar Parawangi ${ }^{1}$, Mappamiring ${ }^{2}$ \\ \{parawangianwar@gmail.com ${ }^{1}$ \} \\ Universitas Muhammadiyah Makassar ${ }^{1,2}$
}

\begin{abstract}
This research entitled Implementation Model of Poor Farmers Empowerment Program (Case Study of Commodity Development in District Strategic Area in Bone). This study aims to answer the problem that the implementation of District Strategic Areas (KSK) program, not always in line with what is planned, or not in accordance with the vision with reality. This study will identify how the behavior of organizational and inter-organizational implementation in determining the success of the Commodity Development Program in the District Strategic Area (KSK) in Bone. The method used in this study is descriptive qualitative and relevant types of research. Data validation is done by the triangulation technique. A qualitative approach by observation and in-depth interviews are used to obtain valid data and information. The District Strategic Area (KSK) is an area that has potentials and prospects to activate local economic activities in districts, in order to reduce poverty, reduce unemployment, and spur regional development to reduce regional disparities. The results show that the activities recorded in the development of district strategic areas in Bone District as a coordinated, aspirational and democratic program have not been fully realized. Growth of development at the local level, especially among poor farmers in terms of organizational and inter-organizational capability as the responsible program, has not shown any commitment and coordination with related institutions in a program.
\end{abstract}

Keywords: Empowerment, Poor Farmers, Commodities

\section{Introduction}

Since the introduction of regional autonomy policy, every region from provincial level to regencies / municipalities is expected to be able to explore its regional potentials in an effort to increase regional income, as it tackles the welfare of the community. In addition, it is also expected to be able to handle any problems that arise as the impact of development activities. Introduction to the potential of the region, has a purpose that can be excavated to give birth a strength and excellence to bring the community become empowered. This introduction may give birth to constraints or weaknesses as valuable input to formulate strategies to achieve the established development goals.

Lately there are indications of strengthening the problem or weakness of poverty alleviation in Indonesia. This is one of the public issues that has not been resolved until now. 
The poorest people in South Sulawesi are mostly in rural areas, namely in 2016 the poor population of 24.76 percent, while urban areas amounted to 8.98 percent. In its development, in the year 2017 the number of poor people in rural areas as much as 25.24 percent, while in urban as much as 13.72 percent. The number of impoverished inhabitants predominantly with major livelihoods in the agricultural sector, which has a land area of less than 0.4 hectares.

A policy in the field, sometimes different from previous expectations. This is due to the distortion of the policy implementation. This is an important issue for implementation experts to address, so that a policy design can be applied successfully. Some arguments try to modify a policy in the implementation process by reflecting on the actual conditions. But it can not be done primarily in adding value to the policy[1], [2].

In other words, looking at the policy is like doing something that is not clear. One reason for the vagueness of the policy objectives, and the conflict between the implementor itself [3], [4]. Even Mazmanian and Sabatier [5], in his study identified an error that arose. According to him, one of the models seemed naive and unreal, the intervention of policy makers in implementation. This ignores the ability of a number of implementors and takes part in the process of implementing structuralization Moe, [6]. In Mazmanian and Sabatier [5], Van Meter and Van Horn [7], assess the implementation is not limited to policy points alone, but rather as a very complex link in implementing and evaluating indirectly with factors that are not in the rules (an unsupportive political environment).

For that, both Elmore [8], Goggin et al, [9], May [10], Stoker [3], says that a policy implementer who lacks expertise in dealing with every problem, will be faced with a number of difficulties in implementation. Whether that's an unclear purpose or a very complex implementation structure. The Government has also intervened this issue from 'OrdeBaru' to this 'OrdeReformasi'. But it has not produced satisfactory results, even the poor do not change significantly both in quality and quantity. This shows the weakness of the implementer who does not understand exactly the desire of a policy, ie what kind of expectations the policy is to achieve the program objectives.

This is where the ability required of organizational and inter-organization Behavior. That is, the development of policy implementation is highly dependent on organizational resources, which participates with the ability to build a network of interrelated links [11].

\section{Method}

The object of this research is poor farmer community. They are considered able to provide more information. The research was conducted in the District Strategic Area: Palakka, Barebbo and Awangpone, Bone. The method used is a qualitative method, with the reason that the problems that arise related organization and inter-organization in the empowerment program of poor farmers are often found in "process", so it is more appropriately approached qualitatively. Strategies used to answer the problem or achieve the research objectives that have been determined is a case study. As stated by Yin [12], that "an empirical inquiry that investigates phenomena in a real-life context".Village, and Bengkuring area, the main areas affected by the biggest floods in Samarinda.

\section{Result and Discussion}

\subsection{Organizational Commitment}

The commitment of KSK program implementers is mutual agreement with related institutions in maintaining the stability of the organization and network among the existing 
organizations, in relation to the implementation of the KSK program in Bone. Not easy to maintain the stability of the network, because of course there are various interests carried by each agency involved. This is where the agency's commitment is needed not to prioritize the interests of each in achieving the program objectives in the region. That is why, so the Chairman of the Committee for the development of commodities in the area of KSK Kabupaten Bone A.Suria Dharma, revealed that: "All agencies involved in the program have not implemented the development of physical infrastructure and social-economic potential in synergy. Even the implementing agencies have not fully coordinated the program, either to the public or to potential investors. Socialization is done only when there are other activities in related institutions. It is remembered for the sake of time and cost efficiency, no need to mobilize the target group. Similarly, in terms of effective energy and different activities, can be done at the same time.

The data indicates that the main program of KSK Socialization was not done in a planned manner. The activity is only a 'followup' activity in other institutions. In response, A. Suria Dharma is not 'passimis' and remains confident that Bone will do and can increase economic growth in agriculture and livestock. In the current economic growth Bone has reached 9.06 percent at the same time can suppress inflation up to 1.48 percent.

Based on the results of the above interviews, it is clear that without any commitment, it is impossible that the implementation of the KSK development program can run maximally. Therefore, there must be a commitment of organizations and inter-organization of KSK programs implementer that are marked by a Memorandum of Understanding (MoU) in running the program, so that social problems in the region can be resolved quickly.

Meanwhile, the Assistant of Administrator Muh. YaminThahir, argues that: the element of commitment is essential to each program implementing agency, especially in the use of the budget to avoid misunderstanding between them. Because if this condition manifests it will give birth distortion which in turn hampers the implementation of the program.

The results of interview above, both A. Suria Dharma and YaminThahir remain optimistic in the field of food. Even Bone became the target of food self-sufficiency 1 million tons per year. And it has been followed up. As a result, in 2017 the Government of Bone can award as a food self-sufficient region that succeeded 1.2 million tons of rice during the Year 2016.

\subsection{Organizational Coordination}

One of the most urgent factors in inter-organizational networks and influencing the determination of regional economic growth strategy is coordination, organizations depend on organizational culture and behavior that can also make organizations grow in the area of learning organizations [13], [14]. Coordination is done with cross-sectoral organizations as the implementer of the KSK program is bound in the regional economic growth network. Coordination is carried out, both in terms of decision-making, especially in the provision of data and information or in terms of implementation activities.

The ability of the coordination system in the implementation of local economic growth strategy is determined by the integration of the potential of local economic resources and the integration of its activities as external investor facilitator. This has been proven, based on the results of the research, that the Secretariat team and the coordination team as the executor of the KSK program do not get investors who can protect the poor farmers, especially in the KSK areas with their own efforts to date.

Though referring to the recommendation Osborne \&Gaebler [15], to show entrepreneurial spirit. The role of cross-sectoral organizations on the development of KSK is important. The Bone Regent with the authority of its own authority gives full mandate to the relevant 
organizations under the control of the Secretariat Team, to coordinate with their togetherness in planning and implementing the activities of the KSK program. The above matter is important, because in Bone there are three areas of KSK namely; Palakka, Barebbo, and Awangpone. All three of them have different types of potential economic resources. Stakeholders expect to coordinate data such as regional potentials, investment activities, business opportunities, and market opportunities. Thus, the success of the secretariat team in facilitating investors to the three areas of the KSK in Bone Regency, it is necessary mapping the potential of economic resources in the region. This potential, is an integral part of policies and programs and activities, as an organization based network system between organizations.

On the other hand, the development of the District Strategy Area by looking at aspects of community development can be through; participatory approaches aimed at strengthening community capacity, strengthening community institutions, developing partnerships, and others. Such community development, directed toward society with a mental attitude and productive behavior, efficient, environmentally careful, and modern-minded, while maintaining and developing positive values already developed within the community itself.

\section{Conclusion}

The District Strategic Areas (KSK) are areas in the districts that are considered to have potential and prospects to enable local economic activities in the districts, in order to reduce poverty, reduce unemployment, and spur regional development to reduce regional disparities. The implementing organizations of the KSK program in carrying out its various programs, such as the Coordination Team, the Secretariat Team, and some SKPD (Bone Regional Work Unit) of Bone Regency, are directly related to the KSK program as one of the efforts in local economic growth. However, the research results show that this organization has not given serious attention in determining/implementing and implementing strategies in the context of regional economic growth in Bone. One indication that there is no investor ready to invest in this region. One cause is in the determination of strategy or decision, this organization is still dominated by bureaucratic culture that is top-down decision making model.

\section{References}

[1] D. J. Palumbo and D. J. Calista, "Opening Up the Black Box: Implementation and the Policy," in Implementation and the Policy Process Opening Up the Black Box., 1990, pp. $3-18$.

[2] A. Schnider, Larason, and H. Ingraham, Policy Design for Democracy. Lawrence, KS: University of Kansas Press, 1997.

[3] S. P.Robert, Reluctant Partners, Implementing Federal Policy. Pittsburgh: University of Pittsburgh Press, 1991.

[4] Pressman, L. Jeffrey, Wildavsky, and Aron, Implmentation Berkeley. California: University of California Press, 1973.

[5] D. A. Mazmanian and P. A. Sabatier, Implmenetation and Public Policy. Glenview II: Scott Foresman, 1983.

[6] T. M. Moe, "The Politic of Bureaucratic Structure," in Can the Government Govern?, John E Chu., Washington. DC, 1989.

[7] "The Policy Implementation Process: A Conceptual Framework," Adm. Soc., vol. 6, pp. $445-68,1975$.

[8] R. F. Elmore, “'Instrument and Strategy in Public Policy,' Policy Studies Review,” 
vol. 7, no. 1, pp. 174-86, 1987.

[9] M. L. Goggin, A. O. M. Bowman, J. P. Lester, and J. O'Toole, Lawrence, "Implementation Theory and Practice: Towards a Third Generation," Glenview, Il. USA: Scott, Foresman \& Co, 1990.

[10] P. J. May, "Can Cooperation Be Mandated? Implementing Intergovernmental Enviromental Management in New South Wales and New Zealand," PubliusThe J. Fed., vol. 25, no. 1, pp. 89-113, 1995.

[11] S. C. Winter, "Implementation perspectives: Status and reconsideration," Sage Handb. public Adm., vol. 265, no. 3, 2012.

[12] R. K. Yin, Case study research: Design and methods (applied social research methods). London and Singapore: Sage, 2009.

[13] M. F. Akbar and W. K. Mohi, "The Effectiveness of Local Government Organizing Through the Learning Organization Perspective at the Regional Secretariat Office of Gorontalo Regency,” Saudi J. Bus. Manag. Stud., vol. 3, no. 9, 2018.

[14] Z. Nahruddin and H. Tambajong, "The Behavior of Apparatus and Cultural Organization in Provision of Public Service in District Level," Sch. J. Arts, Humanit. Soc. Sci., vol. 5, no. 7b, pp. 716-720, 2017.

[15] Gaebler, "Reinventing government: How the entrepreneurial spirit is transforming government," Reading Mass,.” 1992. 